\title{
The influence of percutaneous mitral repair programs on mitral surgery volume: What should we expect and what can we do?
}

\author{
Leonid Sternik, MD
}

\author{
From the Department of Cardiac Surgery, Sheba Medical Center, Tel HaShomer, Ramat Gan, Israel. \\ Disclosures: Author has nothing to disclose with regard to commercial support. \\ Received for publication Aug 31, 2015; accepted for publication Aug 31, 2015. \\ Address for reprints: Leonid Sternik, MD, Department of Cardiac Surgery, Sheba Medical Center, Israel (E-mail: \\ leosternik@hotmail.com). \\ J Thorac Cardiovasc Surg 2015;150:1098-9 \\ $0022-5223 / \$ 36.00$ \\ Copyright $(c) 2015$ by The American Association for Thoracic Surgery \\ http://dx.doi.org/10.1016/j.jtcvs.2015.08.115
}

Recent developments in transcatheter repair and replacement of heart valves have significantly influenced surgeons' and cardiologists' decision-making processes. These days, it is not clear whether or not a patient must undergo surgery if he or she requires correction of an aortic or mitral valve. Downs and colleagues ${ }^{1}$ report on 468 patients who were referred over the past 7 years for procedure utilizing the MitraClip device (Abbott Laboratories, Abbott Park, Ill) at their institution. Of these, 156 patients $(33.3 \%)$ received a MitraClip device and 82 patients $(17.5 \%)$ underwent surgical intervention. During this time, the volume of isolated mitral valve operations significantly increased from 50 procedures in 2007 to 93 procedures in 2014 (an 80\% increase; $R^{2}=0.89$ ). In response to a reviewer's question about other factors that could possibly be influencing this increase in mitral surgery, the authors replied that over the time period studied the basic components of the cardiac surgical group remained stable, with essentially the same core faculty, a stable regional referral base, and no major changes in competing cardiac surgical practices. Furthermore, isolated coronary artery bypass grafting volumes remained stable over time at the authors' institution. Downs and colleagues ${ }^{1}$ listed several reasons for mitral surgery after MitraClip referral. Some patients were, in fact, at low risk or moderate risk and relatively young. Other reasons for mitral surgery included leaflet anatomy not suitable for use of the MitraClip, mitral valve area measurements too small, severe coexisting tricuspid regurgitation, severely reduced ejection fraction requiring other advanced therapies such as implantable left ventricular assist device, and prolonged waiting periods for MitraClip due to trial limitations. ${ }^{1}$ The authors do not have enough data to follow the exact changes in referral patterns from each referring center and physician; however, the increase in mitral surgery volume at their institution appears obvious to me.

Conradi and colleagues ${ }^{2}$ in their recent study from Germany also reported that mitral surgery volume increased with MitraClip introduction. There are reports describing mitral surgeries after failed MitraClip procedures, a factor that also may somewhat increase surgical volume. ${ }^{3,4}$ In

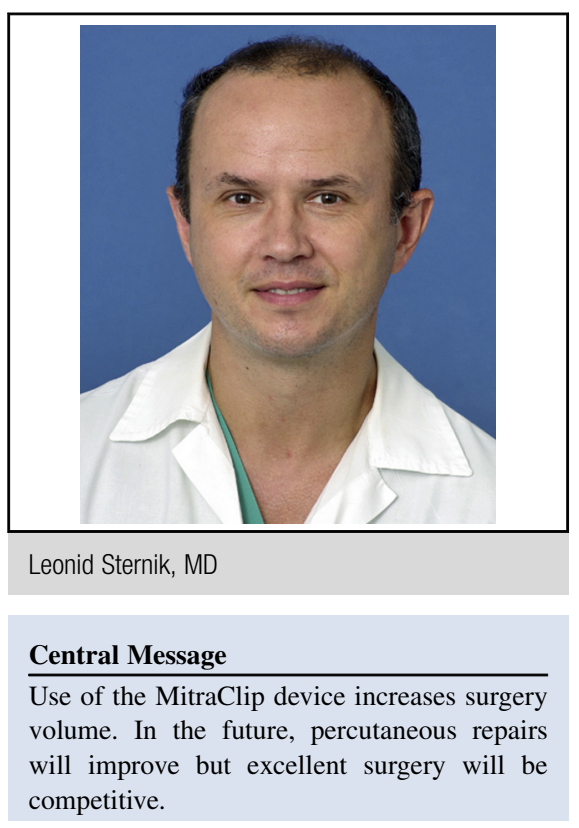

See Article page 1093.

the report by Downs and colleagues, ${ }^{1}$ mitral surgery following MitraClip was required in 5 out of 156 patients $(3.2 \%)$. Naturally, with the development of MitraClip technique, more attention was paid to a group of extremely ill patients with mitral regurgitation. These patients had not been considered for any type of intervention in the past. Now, some of these patients undergo surgery because they are not suitable for MitraClip due to the above-mentioned reasons.

The MitraClip device is a type of percutaneous Alfieri stitch without a ring. De Bonis and colleagues ${ }^{5}$ emphasize the need for reliable annuloplasty to improve long-term outcomes of the currently available transcatheter edge-to-edge procedure. Residual mitral regurgitation, after MitraClip placement, is a risk factor for adverse outcome. ${ }^{6}$ Several promising techniques for transcatheter annular ring placement are currently being developed, in addition to the artificial cordae implantation technique. ${ }^{7,8}$ I believe the results of percutaneous mitral repair will improve with these developing techniques. This increase of surgical volume with MitraClip introduction may disappear in the future. To stay in business, surgeons will have to demonstrate excellent results of mitral surgery; that is, low mortality and morbidity, in this group of very ill patients. ${ }^{9}$ In all likelihood, the operative mortality of surgery will always be 
higher than that of transcatheter procedures, but event-free survival and freedom from mitral regurgitation and stenosis can be better after surgery than in transcatheter procedures, even in early and midterm follow-up. Another important issue introduced by the development of percutaneous technique of valve repair is a disease-oriented approach. Currently and in the future a mitral team, aortic team, and coronary team will be required. Surgeons and cardiologists must work together to decide which approach is better for the patient: surgery or percutaneous technique. If a patient was referred for percutaneous repair but was found to be a candidate for surgery, should this patient be operated on at the referral center or is it better to send the patient back to his/her cardiologist to be operated on by his/her local surgeon?

These issues require good lines of communication between cardiologists and surgeons. There are many very ill patients who are not candidates for surgery due to comorbidities, age, and other factors. We must collect more data to ensure that MitraClip and other percutaneous valve interventions are indicated. Is there a significant influence on quality of life and survival? Perhaps in elderly and very ill patients medical treatment would be the best option.

I agree with Downs and colleagues ${ }^{1}$ that the MitraClip device does increase the volume of mitral surgery at the present time. I believe that future development of percutaneous mitral repair techniques, including rings and artificial cordae, may lead to some decrease in surgical referrals. To stay in business, surgeons will have to demonstrate excellent results. Heart teams and disease-oriented teams of surgeons and cardiologists will be necessary in the future for optimal patient care.

\section{References}

1. Downs E, Lim S, Ragosta M, Yount K, Yarboro L, Ghanta R, et al. The impact of a percutaneous mitral repair program on surgical mitral valve volume. J Thorac Cardiovasc Surg. 2015;150:1093-7.

2. Conradi L, Lubos E, Treede H, Pietzsch JB, Weber S, Pietzsch M, et al. Evolution of mitral valve procedural volumes in the advent of endovascular treatment options: experience at an early-adopting center in Germany. Catheter Cardiovasc Interv. April 28, 2015 [Epub ahead of print].

3. Geidel S, Schmoeckel M. Impact of failed mitral clipping on subsequent mitral valve operations. Ann Thorac Surg. 2014;97:56-63 [Epub ahead of print].

4. Alozie A, Westphal B, Kische S, Kaminski A, Paranskaya L, Bozdag-Turan I, et al Surgical revision after percutaneous mitral valve repair by edge-to-edge device: when the strategy fails in the highest risk surgical population. Eur J Cardiothorac Surg. 2014;46:55-60.

5. De Bonis M, Lapenna E, Pozzoli A, Giacomini A, Alfieri O. Edge-to-edge surgical mitral valve repair in the era of MitraClip: what if the annuloplasty ring is missed? Curr Opin Cardiol. January 8, 2015 [Epub ahead of print].

6. Paranskaya L, D'Ancona G, Bozdag-Turan I, Akin I, Kische S, Turan GR, et al Residual mitral valve regurgitation after percutaneous mitral valve repair with the MitraClip system is a risk factor for adverse one-year outcome. Catheter Cardiovasc Interv. 2013;81:609-17.

7. Buzzatti N, Taramasso M, Latib A, Denti P, Guidotti A, Alfieri O, et al. Transcatheter mitral repair and replacement: state-of-the-art and future directions. J Heart Valve Dis. 2014;23:492-505.

8. Merk DR, Emrich FC, Mohr FW, Seeburger J. Transcatheter mitral valve repair: where are we? Expert Rev Cardiovasc Ther. 2014;12:1379-81.

9. Vassileva CM, McNeely C, Spertus J, Markwell S, Hazelrigg S. Hospital volume mitral repair rates, and mortality in mitral valve surgery in the elderly: an analysis of US hospitals treating Medicare fee-for-service patients. J Thorac Cardiovasc Surg. 2015;149:762-8 